\title{
The Health Landscape of the Islamic Republic of Iran
}

\section{S. Alireza MARANDI ${ }^{1}$}

${ }^{1}$ Professor of Pediatrics (Neonatology), President of the Iranian Academy of Medical Sciences, Iran.

\section{ABSTRACT}

Prior to the Islamic Revolution, hardly any health care system existed in Iran. Preventive health care was very limited, and a fairly decent curative care could only be found in Tehran and, to a lesser extent, in a few large cities where a great majority of the 12-14 thousand Iranian physicians were practicing. The people living in smaller towns and large villages had to seek the advice of expatriate physicians speaking a different language. Poor people in general and residents of more than 65,000 villages had virtually no access to medical care.

When the Islamic Revolution materialized, people rightfully began to expect social justice and health equity, and the Ministry of Health in response started to establish a primary health care (PHC) system throughout the country. However, the main problem was inadequate healthy manpower. As the Ministry of Higher Education was unable to increase the number of students, in 1985, the Parliament passed a law taking away all health education schools from the Ministry of Higher Education and integrated them into the Ministry of Health, forming the Ministry of Health and Medical Education. Almost simultaneously at least one university of medical sciences and health services was established in each province. Since then the chancellors of the universities are responsible for not only health education and research, but also the health care of the entire province.

As a result of the integration, not only Iran became self-sufficient in healthy manpower, but research also became more public health oriented and medical education more community oriented. The integration also led to an improvement in the health condition throughout the country, particularly in the villages, remote areas, and less developed provinces.

Now all villages and towns with less than 20,000 people have access to family practice physicians through the PHC system, and the plan is to do the same for all cities to move closer to the universal health coverage. Effort is also being made to decrease the out-of-pocket expenses from $52 \%$ to $30 \%$.

Recently, the general health policies endorsed by the supreme leader have been communicated. By implementing these policies, a noticeable improvement is expected to materialize in different aspects including management.

Key words: Health care reform, health status, Iran, primary health care, professional education, system integration.

\section{MEDICAL EDUCATION BEFORE THE REVOLUTION}

Prior to the Islamic Revolution, nine medical schools were located in Iran, of which two were fairly newly established. Three schools were located in Tehran, and the rest in the larger cities. The total number of students admitted to these schools was 1207 annually. The number of other health education schools such as dentistry, pharmacy, nursing, and midwifery was even more limited. These health education schools were also located mainly in Tehran and a few larger cities. The total number of health-related faculty members was 2552. 
The curricula and quality of medical education were unrelated to the health condition and needs of the community. In fact, the quality of education was measured on the basis of the percentage of the medical school graduates passing the ECFMG Examination and being accepted in US residency training programs. The Medical School of Shiraz University (then called the Pahlavi University) was proud to have an average of $91 \%$ of their graduates accepted in US residency programs. The Medical School of Tehran University, as the oldest and the largest medical school in the country, accepted 300 students annually, and was second in the percentage of graduates accepted in US residency programs. Unfortunately, at that time the road to the United States and a few Western European countries was a one-way road and almost none of the graduates returned. Due to the fact that medical students were trained mainly in sophisticated university hospitals, they were not capable of responding to the everyday needs of the community. In other words, the medical schools did not feel responsible toward, or accountable for, the broader needs of the country. Due to the loss of so many Iranian physicians, foreign physicians, who did not even know the local language, had to be hired.

\section{THE hEALTH CARE SYSTEM BEFORE THE REVOLUTION}

Prior to the Islamic Revolution, Iran hardly had a health care "system." Preventive health care was very limited, and services were not accessible to everyone, particularly the poor and underprivileged. A fairly decent curative care system could only be found in the capital city of Tehran and, to a lesser extent, in a few large cities where a great majority of the 12-14 thousand Iranian physicians were practicing.

The people living in small towns and large villages had to seek the advice of foreign physicians who, for the most part, spoke a different language. Poor people in general and particularly the residents of over 65,000 villages had very limited access to medical care.

\section{ESTABLISHING THE PHC SYSTEM}

When the Islamic Revolution materialized, naturally people began to expect better health care services. However, soon the imposed war began, leading to heavy civilian casualties on a daily basis, on the one hand, and the emigration of a fairly large number of Iranian physicians, on the other. To achieve "Health for All," the Ministry started to establish a PHC system throughout the country, in spite of a severe shortage of healthy manpower.

The PHC system was based on the experiences obtained from the West Azerbaijan project. Several years prior to the Islamic Revolution, the Ministry of Health, in collaboration with the School of Public Health (University of Tehran) and the World Health Organization (WHO), initiated a pilot project in a number of villages in the District of Orumiyeh (West Azerbaijan Province). In this project, local community health workers called "behvarz" were responsible for the health care of the villagers, and their services were rendered in so-called "health houses." Each health house had two behvarzes. The female behvarz was mainly responsible for maternal and child health, and the male behvarz was in charge of environmental and occupational health of the catchment area. The behvarzes conducted an annual census in their catchment areas and also recorded vital events such as births, deaths, and family planning information on a form called vital horoscope, which was placed on the wall of the health houses.

To become a behvarz, one should have passed at least 5 years of primary school, followed by 2 years of training in the local Behvarz Training Center. Their training included theoretical as well as practical aspects, and their performances were always supervised closely by their instructors. Once a month, all behvarzes gathered in the Behvarz Training Center for in-service training. The center also collected all information and data from the health houses and offered the behvarzes proper feedbacks. This pilot project led to a significant improvement in all health indices, particularly the maternal mortality ratio and infant mortality rate of the villages. Witnessing this success, in 1984, 
the Ministry of Health made some modifications in the pilot project. Subsequently, each health house became responsible for the health care of about 1500 villagers, residing in at most 4 or 5 close-by villages, including the main village. The distance between these villages was a maximum walking distance of $1 \mathrm{~h}$ from the main village where the health house was located.

Larger villages had rural health centers as well. Each center usually covered 5 heath houses, with a total population of about 7500 people. The rural health centers received patients referred from the health houses and offered feedbacks in response. They also obtained information from the heath houses and forwarded them to the district health centers. The rural health centers were usually staffed by one or more physicians and a variety of health technicians trained in different health education fields.

In the cities, urban health centers were established with similar functions as the rural health centers with two main exceptions: first, each urban health center covered a population of about 12,500, and second, their services were not actively rendered. It is worth mentioning that the private sector was very active in the urban areas, and families usually used private services for curative care and urban health centers for preventive care. Urban health centers functioned under the supervision of district health centers. All district health centers were technically functioning under the provincial health centers, while officially, the same as district hospitals, they were functioning under the office of the district health network.

When the Ministry of Health decided to implement the PHC system, Iran was suffering from a fairly severe shortage of healthy manpower in general and physicians in particular. At that time, the ratio of physicians to the population of the country was $1 / 2800$. With the exclusion of Tehran, the ratio was $1 / 4000$, and in some provinces, it was as low as 1/18,000. A number of provinces did not have even one practicing obstetrician, anesthesiologist, and so forth.

\section{A GREAT OPPORTUNITY}

At this point, the Supreme Council of Cultural Revolution was established, whose main goal was to bring about major reforms in higher education. The medical branch of the Supreme Council, which consisted of university professors, and health and education experts, gave consideration, in detail, to the future of health and medical education. They reviewed nearly 200 proposals received from university professors and other experts. The Council finally concluded that one of the main obstacles depriving people of appropriate health care was the fact that the health care system was separate from medical education. Therefore, they decided to propose the integration of the Ministry of Higher Education's entire health education program into the Ministry of Health.

Since the Ministry of Higher Education was against the idea of integration, before sending this proposal as a bill to the Parliament, the Ministry of Higher Education was asked to increase the number of health education students in general and medical students in particular. To help this happen, the Ministry of Health made special efforts to transfer every facility, including hospitals, that the Minister of Higher Education had requested as a prerequisite for increasing the number of students. As anticipated, the efforts of the Ministry of Higher Education did not amount to a proper solution to the problem. Therefore, the Ministry of Higher Education also agreed to proceed with integration.

\section{A MAJOR EVENT}

In 1985, with the approval of the Parliament, all health education schools and institutions were taken from the Ministry of Higher Education and integrated into the Ministry of Health, forming a new ministry called the Ministry of Health and Medical Education (MOH\&ME). Almost simultaneously, at least one university of medical sciences was established in each province.

At first, the provincial health organizations continued to function and cooperate alongside the university of medical sciences in each province. During the second stage of the transformation of the Ministry, the chancellors of these universities were appointed as representatives of the Minister of Health and Medical Education, and had the authority of appointing the director general of the provincial health organizations. 


\section{ANOTHER MAJOR STEP}

Finally in 1994, provincial health organizations and the universities of medical sciences were integrated, and universities of medical sciences and health services (UMS\&HS) were established. Since then, the chancellors of these universities are responsible for not only education, student affairs, and research, but also the health care of the population of their entire province.

\section{GRADUAL CHANGES FOR THE BETTER}

Many of the university faculty members were taken on tours of the community to study the PHC, and particularly to see health houses, where behvarzes offered fairly effective PHC services to the villagers, and simultaneously collect a variety of healthrelated information about the population under their care.

The visiting faculty members, who were often critical of integration at first, became very impressed, and some of them even became advocates of the system. As a result, some gradual changes began to take place.

\section{EDUCATION}

Some of the faculty members became involved in teaching the students in the community and within the PHC system. The more exposure the faculty members had, and the more experience they gained, the more community oriented their education became. As time passed, even the curricula began to change. In some universities, the curriculum changed dramatically, and the students began to spend a lot of their time in the field of PHC.

\section{RESEARCH}

As faculty members became more familiar and involved with the PHC system, some changes were noted in the types of research they were conducting. The research topics and methodologies became more applied and community oriented. The success of programs related to iodine deficiency disorder, neonatal screening for hypothyroidism, phenylketonuria, and glucose6-phosphate dehydrogenase deficiency is the results of such changes in the direction of academic research. The same is true for many of the communicable disease-related studies.

\section{HEALTH CARE AND MANAGEMENT}

As faculty members became more knowledgeable about the national health situation and its problems, the MOH\&ME developed many different scientific committees related to a variety of health-related issues. Faculty members were invited to become members of these committees, which helped the committees to become more sound, scientific, and convincing in their discussions and decisions. Different health-related programs/departments in the MOH\&ME benefited from the active participation of faculty members. In this process, the faculty members became strong supporters and advocates for the health-related programs/interventions at the country level.

As mentioned previously, the integration has made decisionmaking and coordination in the area of health and healthy manpower training much easier and led to many achievements in the following areas.

\section{ACHIEVEMENTS AND STRENGTHS \\ Healthy Manpower Training}

- The number of medical schools has increased from nine at the time of the Islamic Revolution to 80 at present, 46 of which belong to the $\mathrm{MOH}$ and $\mathrm{ME}$.

- Currently 58 UMS and HS are present in the country with at least one located in each province. Also, 16 faculties of medical sciences are affiliated to the $\mathrm{MOH}$ and ME.

- The number of teaching hospital beds, which was 9558 in 1979 , is now 53,902 .

- The total number of students admitted to the UMS and HS in 2015 was 43,400, of which about 60\% were girls.

- The number of faculty members increased from 2552 in 1979 to 17,863 in 2015 , about $37.7 \%$ of them being female.

- The ratio of faculty members to the 100,000 students is now 1 to 9435 .

- Faculty members have become more involved in community problems. 
- By modifying the curricula, more attention has been paid to the different aspects of health.

- Not too long after integration, the following educational programs have been either developed or expanded throughout the country:

* The development and expansion of 49 different specialty care-training programs. Out of 12,990 residents, $58 \%$ are female.

* The creation of 34 different subspecialty-training programs. Out of 886 fellow residents, $35 \%$ are female.

* The establishment of 99 fellowship-training programs with 722 fellows, of which $36 \%$ are female.

* The creation of 84 PhD programs in health-related areas. Prior to integration, only one PhD program was available. The total number of PhD students is now 6663, of which 58\% are female.

- Students spend 1 month of their training and also 1 month of their internship in a variety of community settings, particularly in PHC centers.

- Skill laboratories have been established in all of the UMS and HS to better prepare the students for clinical courses.

- In addition to regular examinations, medical students must go through a comprehensive examination after their completion of the basic sciences as well as prior to their internship, residency, and fellowship program, for annual promotion during residency training, and finally the specialty and subspecialty boards. Almost all of these tests are regularly performed on a national basis.

- Education development centers have been established in all UMS and HSS.

- Continuous structured training courses have been provided for faculty members.

- The law for continuous medical education has been passed and is being implemented.
- A total of 627 research centers have been established in different UMS and HSs. More attention is being paid to applied research as well as health system research.

- The number of published articles in Institute for Scientific Information and PubMed, which was 341 in 1998, has increased to 9794 in 2014. The number of published articles in Scopus has increased from 331 in 1998 to 13972 in 2014.

- Research methodology workshops are frequently being held in all UMS and HSS.

\section{RESULTS}

- The country has become self-sufficient in healthy manpower.

- Integration has also created an opportunity for the Ministry of Higher Education to increase the annual admission rate of its universities.

- Almost all districts have become more or less self-sufficient in the area of specialty care, and the provinces are self-sufficient in subspecialty care.

- Establishing at least one UMS and HS in each province has contributed significantly to the development of provinces in general and their health services in particular. In 1977, the literacy rate in Iran was 35.5\% among women and 58.9\% among men. In 2011, the adult literacy rate increased to $81.1 \%$ for women and $88.4 \%$ for men.

\section{Public Health}

- The social accountability of universities has increased.

- UMS and HSS are increasingly involved in the process of community leadership, intersectoral collaboration, and partnership building for health improvement.

- UMS and HSs have brought advanced health services to even the most deprived provinces.

- Academic experts and faculty members hold managerial and policymaking positions in the health system from the ministerial level down, and this has helped academicians to become more familiar and involved with public health issues. 
- Almost simultaneous with integration, the PHC network has developed and expanded throughout the country. This network consists of 3800 rural health centers, 17,443 health houses in the villages, 1955 health posts in slum urban areas, 3230 urban health centers, and 440 district health centers. As part of the PHC network, a referral system was planned from the beginning, but due to a shortage of medical manpower, its implementation was postponed until recently when an adequate number of physicians became available. At present practically the entire population of the country has access to health care system.

- Safe drinking water, which was a luxury for much of the urban population in the past, is now available to $99 \%$ of the urban and $96.4 \%$ of the rural population (98.2\% of the total population).

- An appropriate data gathering system (vital horoscope) has been developed at the level of health houses and rural health centers as a tool for assessing the health status of the villages and, ultimately, planning. Medical students and researchers can also benefit from this information in their studies.

- The children's immunization rate was between $2 \%$ and $25 \%$, while currently it is between $98 \%$ and $100 \%$.

- The neonatal mortality rate, which was 51 per thousand live births in 1984, declined to 9.5 in 2015.

- The infant mortality rate declined from 120 per thousand live births in 1977 to 15 per thousand in 2012.

- The mortality rate of children younger than 5 years reduced from about 174 per thousand live births in 1977 to 16 per thousand in 2015.

- The maternal mortality rate decreased from 255 per 100,000 live births in 1976 to 19.5 per 100,000 in 2015.

- The population growth rate, which was 3.9\% in 1986, reduced to $1.3 \%$ in 2012.

- The life expectancy, which was 57.44 and 57.63 years for women and men, respectively, in 1977, increased to 76.5 and 72.17 years, respectively, by the year 2013 (average 74.3 years). Although one cannot claim that the only factor leading to such a dramatic improvement in the health situation and the health statistics in the Islamic Republic of Iran was the integration of medical education into the health services, it was undoubtedly the most influential factor.

The presence of faculty members in the field and their close cooperation and collaboration with health experts and health workers, their involvement in different national and provincial health committees, and their involvement in the different levels of health management led to major changes in medical education and, even more importantly, in the health situation of the country.

\section{CURATIVE CARE}

The progress and achievements have also been remarkable in the area of curative care, although much more efforts to improve the situation are required. Prior to the Islamic Revolution, and also during the 8 years of the imposed war, a fairly large number of patients had to travel abroad for medical care. Many of these types of care were offered inside the country, such as infertility treatment, organ transplantation, and so on. However, on one hand, the demand for an extensive and high-quality medical care rightfully increased following the Islamic Revolution, and on the other, the country was not advanced enough in different aspects of curative medicine to respond to all these needs. The economic cost of sending a fairly large number of patients abroad for sophisticated medical care was also fairly high.

Fortunately, by establishing new universities, expanding the existing specialty trainings, and establishing a variety of new specialty trainings, along with founding subspecialties and fellowships in different fields, the country soon became selfsufficient in practically all aspects of curative care. Gradually the quality of care also improved to the point that these days many Iranians living abroad - including those living in industrialized countries - and also a fairly large number of non-Iranians travel to Iran for medical care.

\section{CHALLENGES@ AND RECOMMENDATIONS®}

To increase the enormous benefits of integration, the challenges should be identified and appropriate measures taken: 
- C -The High Council of Community-Oriented Medical Education is not functional at present.

- $\mathbb{R}$-This council should be reactivated, and every effort made to make health-related training, including medical education, as community oriented as possible.

- (c)-The link between the community and the local health facilities still needs to be improved.

- $囚$-Community and health care providers at the local level need to be educated and made partners in local health planning processes.

- (C)-The medical curriculum is not completely community oriented. In addition, lack of incentives for participation of faculty members is among the major challenges.

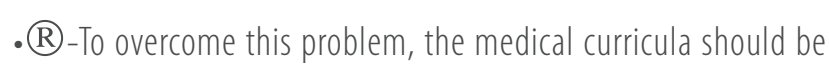
revised and proper facilities and incentives should be provided for faculty members to facilitate their active participation in the field and also the ambulatory care-training activities.

- C-The engagement of faculty members in their own private practice is also a challenge.


faculty members to give up their private practice.

- (c)-Full integration has not materialized yet at every level of education, health care, and management.

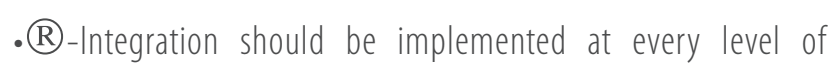
education, health care, and management.

- C-The weak referral system is not responding to the needs of the community.

- $\mathbb{R}$-The stratification of the services and referral system needs to be implemented throughout the country.

- (c)-Insufficient involvement of universities in community participation and intersectoral collaboration is a concern.

- $\mathbb{R}$-Universities should be made more accountable to the community as well as more interested in community participation and intersectoral collaboration. They should be encouraged to play leadership roles in this regard. Research on community ownership for health development and intersectoral action for health needs to be encouraged.

- C-The quality of health care is not desirable, and adequate well-trained healthy manpower is not available in some health care facilities.

- $\mathbb{R}$-To improve the quality of health care and healthy manpower training, a higher percentage of the national gross domestic product should be allocated to the health care system and also to the medical education.

- C)-Inequity in access and utilization of health services is still a major challenge.

- (R-To move toward health equity, health insurance should improve and out-of- pocket payments, particularly for ambulatory care, should be significantly reduced. Also, as an incentive for physicians and other health workers to reside and work in the remote and deprived areas, living conditions in these areas should be made attractive for them.

\section{EVALUATIONS OF THE INTEGRATION}

Like most new actions or reforms, the aforementioned integration was quite controversial right from the beginning. Its opponents even tried more than once to disintegrate the $\mathrm{MOH}$ and $\mathrm{ME}$ through the Parliament, but with no success.

By and large, the main arguments voiced by the opponents of the integration seem to be unscientific and often based on rumors. Some opponents somehow believe that if healthy manpower training is handed over to the Ministry of Higher Education, all financial, managerial, and educational problems will be solved. A number of years ago, a newly appointed Minister of Health and Medical Education and his deputies (who were, at the time, strong opponents of the integration), conducted three different researches on this issue. The results of these researches were very convincingly in favor of continuing the integration. These results along with the experience gained by the Minister's team changed their minds completely and they became very strong supporters of the integration. They made their opinion known to the President, and also the Parliament. 
In spite of these investigations and researches, some faculty members continued their efforts in favor of disintegration. As a result, the MOH and ME asked for the support of the WHO Eastern Mediterranean Regional Office to carry out a comprehensive and impartial evaluation of the integration. An evaluation team was formed, which was composed of a national advisory team and a group of international consultants.

The aim of the team was to study the country's:

- health services governance, delivery, resources, and partnership;

- medical education governance, process-outputoutcomes, resource management, and partnership; and

- interests and expectations of major stakeholders.

More than 200 major stakeholders, including opponents and proponents, participated in the study. Different methods, including open discussions, small (focus) group work, site visits, individual approaches, and questionnaires, were used.

At the end of the evaluation, the concluding statement by the international team was that the "strengthening of the existing system and improving performance is more likely to benefit the country and population at large." They also stated that "the separation of the medical education from health services will exert a huge negative impact in strategic, technical, financial and logistic terms."

They strongly recommended that "the Government should support the system of integrated health services and medical education, and to urgently review and upgrade the current curriculum through the introduction of community oriented, problem-based and other effective learning strategies.".

\section{THE WAY FORWARD}

As defined by the WHO: "Health is a state of optimal physical, mental and social well-being, and not merely the absence of disease and infirmity." According to this definition, health personnel are responsible for prevention and protection along with the promotion of health for the individual as well as the community. However, graduates of medical schools traditionally see themselves as only responsible for curative medicine. This is not necessarily an individual choice, but is largely related to how medical doctors are trained.

Usually the trend is, the sicker the patient, the more sophisticated the equipment; and the more unusual the circumstances, the higher the pride and prestige for the physician. The main reason for this is that almost the entire training program for medical students and residents takes place at the bedside of patients; very less, if any, takes place at appropriate ambulatory care facilities, and none happens at the community level.

After being cured, patients regularly face the same conditions they faced before their illness. They are neither equipped with the knowledge of how to take care of themselves nor properly informed on how to prevent similar situations in future, let alone how to live and enjoy a better life and how to promote their health along with that of their families and community. Mental health is neglected to a great extent, social well-being is not seriously taken into consideration, and spiritual health is practically nonexistent.

If this global picture is to be changed, among other important steps, the curricula of health-related education in general, and that of medical education in particular, should be revised, and training should take place under different settings. To bring about such a major change, universities and health services must work together harmoniously.

The experience of the Islamic Republic of Iran shows that the integration of medical education and health services not only has made the country self-sufficient in health manpower resources, but is also the most appropriate, durable, and economical means of achieving community health at the highest level. Although integration has not yet evolved completely, especially in the periphery, and the situation is still far from being ideal, the results are very encouraging. Even limited exposure so far has helped faculty members and students to become more familiar with the state of health in the community. Their realistic understanding of the environment, culture, traditions, problems, needs, and 
potentials creates an environment for better management and opportunities for solving health-related issues. Therefore, it is anticipated that longer and better-structured exposure for students as well as faculty members to community needs, the revising of the curricula, along with the creation of proper incentives for full-time faculty members may bring about more progressive changes in the outlook of faculty members as well as students. This in turn may lead to a more community-oriented medical education, and help resolve many of the country's health problems.

Although no one can claim that integration is the only solution or that it can by itself solve all of the country's health problems, it definitely is the most economical and realistic solution available. Of course, effective monitoring and evaluation has to be a continuous and integral part of the system.

As the integration concept has been found to be effective and forward looking, the WHO should be supported in its attempts to advocate the adaptation of this approach in the countries of the Eastern Mediterranean Region in accordance with the political, cultural, and economic conditions of these countries.

\section{REFERENCES}

1. Marandi A. Integrating medical education and health services: The Iranian experience. Medical Education, 30(1). MA: Blackwell Science, 1996

2. Marandi A, Azizi F, Larijani B, Jamshidi H. Health in the Islamic Republic of Iran, Tehran, Iran: UNICEF and WHO, 1998.

3. Marandi A. The integration of medical education and health care system in the Islamic Republic of Iran: A historical overview. Journal of Medical Education, 1(1). Tehran, Iran: WHO and Shahid Beheshty University of Medical Sciences and Health Services, 2001.

4. Salafsky $B$, Rawaf $S$, Achour $N$, et al. Integration of medical education and delivery of health services in IR Iran, 17-28 June 2006, 2006.

5. Marandi A, Azizi F, Larijani B, Jamshidi H. Health in the Islamic Republic of Iran, Tehran, Iran: Ettela'at Publisher, 2015. 